\title{
Visual Display Terminal Use Increases the Prevalence and Risk of Work-related Musculoskeletal Disorders among Chinese Office Workers: A Cross-sectional Study
}

\author{
Shanshan $\mathrm{Wu}^{1}$, Lihua $\mathrm{HE}^{1}$, Jingyun $\mathrm{LI}^{1}$, Jianxin $\mathrm{WANG}^{1,2}$ and Sheng $\mathrm{WANG}^{1}$ \\ ${ }^{1}$ Department of Occupational and Environmental Health, School of Public Health, Peking University and ${ }^{2}$ Beijing \\ Centers for Diseases Control and Prevention and Centers for Preventive Medical Research, P.R. China
}

\begin{abstract}
Visual Display Terminal Use Increases the Prevalence and Risk of Work-related Musculoskeletal Disorders among Chinese Office Workers: A Cross-sectional Study: Shanshan Wu, et al. Department of Occupational and Environmental Health, School of Public Health, Peking University, P.R. China-Objectives: Little is known about workrelated musculoskeletal disorders (WMSDs) among computer users mainland China. The aim of this study was to estimate the prevalence of WMSDs in office workers in Beijing, and to determine risk factors for WMSDs in the neck (WMSDs-N). Methods: In a crosssectional study, a self-administered questionnaire was delivered to 720 office workers who use a computer as a main working tool. Odds ratios (ORs) were calculated for risk factors. Results: The prevalence of WMSDs of the neck, shoulder, wrist/hand, upper back and low back amongst office workers were 55.5, 50.7, 31.5, 26.2 and $6.6 \%$, respectively. Both individual risk factor and working condition factors were found to be independently related to WMSDs-N. Conclusions: The WMSDs prevalence rates among office workers in Beijing, China, were high. The most affected area was the neck. Preventive measures for office work should be focused on the neck (e.g., rest breaks).

(J Occup Health 2012; 54: 34-43)
\end{abstract}

Key words: Ergonomics, Musculoskeletal disorders, Visual display terminal

As a new way of working, visual display terminal (VDT) operation has become ubiquitous in the workplace. Since the reform and opening up of China

Received Jun 19, 2011; Accepted Oct 27, 2011

Published online in J-STAGE Dec 10, 2011

Correspondence to: S. Wang, L. He, Department of Occupational and Environmental Health, School of Public Health, Peking University, 38 Xue Yuan Road, Hai Dian District, Beijing 100191, People's Republic of China (e-mail: shengw@bjmu.edu.cn, alihe2009@126.com) in the early 1980 s and the rapid development of science and technology, computers have been applied in various industries. The China National Bureau of Statistics reported that $63.8 \%$ of workplaces used computers in 2007 , and the percentage reached $88.1 \%$ in the finance and business services sector ${ }^{1)}$.

Working in an office environment is widely known to be associated with work-related musculoskeletal disorders (WMSDs), which are a diverse set of conditions characterized by pain, aching, stiffness, fatigue, discomfort, tingling and/or numbness, generally appearing in the fingers, hand, wrist, elbow, arm, shoulder, neck and/or low back ${ }^{2}$. The literature consistently demonstrates that VDT users are at increased risk for neck and/or shoulder symptoms relative to the risk expected in low-exposure office or industrial tasks ${ }^{3,4)}$.

WMSDs in the neck (WMSDs-N) are the most common work-related upper extremity disorders (WRUEDs), and a large range of individual, physical and psychosocial risk factors are associated with the development of WMSDs-N. Individual factors include age, gender, education level, smoking habits and so on; work-related physical factors include awkward posture during work, bending, static sedentary posture and task demands; work-related psychosocial factors include overtime and time spent working to meet deadlines ${ }^{5-7)}$. In addition, several studies have shown that ergonomic factors (e.g., work station design) were possibly linked to WRUEDs ${ }^{8}$.

Although WRUEDs among VDT workers have been a topic in occupational health research for many years and there have been a large number of epidemiological studies on WMSDs, there is still little understanding of the prevalence of WMSDs in different countries. Also, the etiology of WMSDs in computer work is still not completely understood. It is not clear whether the causes of WMSDs are similar in differ- 
ent countries, where the industrial infrastructure and work practices vary ${ }^{9)}$. To our knowledge, no research has analyzed the association between VDT use and problems associated with WMSDs in mainland China, and the risk factors for WMSDs among VDT users in mainland China are still unknown.

The aim of this study were (a) to estimate the prevalence of self-reported WMSDs for office workers who regularly perform VDT work in Beijing and (b) to assess which working conditions and individual factors are associated with WMSDs-N in order to describe approaches for preventive measures.

\section{Methods}

\section{Study population and design}

This was a cross-sectional study focusing on working conditions at typical Chinese VDT workstations. The population of this study consisted of office workers who used VDTs for more than one hour per day in 18 departments of a leading company in the Chinese service industry. Field work was performed in April 2008.

As one aim of the study was to estimate the 12-month prevalences of WMSDs (see measure of outcome), subjects who reported work experience of less than $1 \mathrm{yr}$ at their present job were excluded from the study population. Self-administered questionnaires were delivered to 720 office workers who used a computer as a main working tool. A total of 621 questionnaires were returned $(86.3 \%)$, of which 61 incomplete responses were eliminated, leaving 560 valid questionnaires.

The study was approved by the local ethics committee of Peking University.

\section{Questionnaire}

The questionnaire was used to collect self-reported WMSDs and risk factors.

\section{Measure of outcome}

Symptoms in the neck, shoulders, elbows/forearms, wrists/hands, upper back and low back regions were assessed by a symptoms questionnaire based on the Nordic Musculoskeletal Questionnaire (NMQ) ${ }^{10)}$. The NMQ is the most classic outcome measure for musculoskeletal disorders (MSDs). Participants were surveyed to record whether they had musculoskeletal problems (e.g., ache, pain or discomfort) for the above six regions in the past 12 mo. A participant would not meet eligibility criteria if he/she indicated that musculoskeletal symptoms resulted from a non-workrelated accident/trauma (e.g., sports, traffic accident).

\section{Measure of exposure}

1) Individual factors

The demographic characteristics in the questionnaire included gender, age, height and weight. Body mass index (BMI) was calculated by the formula weight $(\mathrm{kg}) /$ height (meter) ${ }^{2}$. Also, formal education, lifestyle (smoking and physical exercise) and history of musculoskeletal trauma were surveyed ${ }^{11)}$. The worker characteristics were assessed using questions for the general work conditions (e.g., job type, occupational status and occupational history) and duration of employment (e.g., how many years in their current job, work hours per week, work days per week).

2) Working condition factors

The questions used to assess the factors related to an increased risk for WMSDs-N were derived from the standardized Dutch Musculoskeletal Questionnaire ${ }^{12)}$. Questions regarding computer use were based on previous epidemiology studies $^{13)}$. Questions on ergonomic factors (workstation setup) were taken from a workplace health and safety brochure of the Queensland Government, Australia ${ }^{14)}$.

3) VDT use was evaluated in two parts:

a) Current VDT use: Participants were asked how many hours per day and how many days per week they used VDTs. They were also asked whether they had a part-time job. If they did, they were asked whether they used a computer while working and, if so, how many hours per week. Participants were also asked whether they used computers in their leisure time and, if so, for how many hours per day and how many days per week.

b) Accumulated VDT use: participants were asked how many years they had used computers for their current job; this amount of time was multiplied by their hours per week. In addition, they were asked whether they had been VDT users before their current jobs and, if so, for how much time they used VDTs previously. The total time was the sum of their current and previous jobs' VDT time.

Workplace factors were assessed using questions for physical workload (e.g., postures related to the neck region) ${ }^{15)}$ and computer use (e.g., main operating tools, hours per day of VDT use).

Workstation factors were assessed using questions for the monitor position, type of VDT, arm supports and chair characteristics (e.g., having an adjustable back rest and chair height).

As there were very few cases for some response options, several independent variable categories among the questions with more than two response options were collapsed to improve their psychometric properties. 


\section{Statistical analysis}

All statistical analyses were performed by the Statistical Package for the Social Sciences software (SPSS version 11.0). In all analyses, alpha was set at $p$ values $<0.05$ (two tailed).

The results were reported as descriptive statistics. The associations between WMSDs-N (dependent variable) and the various factors (independent variables) were analyzed. Univariate and multivariate analyses were performed to identify risk factors. To assess the relationship between self-reported WMSDs-N and individual factors, workplace factors and workstation ergonomic features, binary logistic regression was used for analyses. The odds ratio (OR) was calculat- ed, and a $95 \%$ confidence interval $(95 \% \mathrm{CI})$ was estimated. A multiple logistic regression model was used to assess the independent work related risk factors. A backward likelihood ratio stepwise method was used. All variables related to WMSDs-N in univariate analyses with $p$ values $<0.15$ were entered into the logistic regression model. Variables were rejected from the model if the $p$ values $>0.10^{16)}$. Only the remaining significant variables were included in the final model.

\section{Results}

Study population

The study population included 237 females (42.3\%) and 323 males (57.7\%). Table 1 shows the demo-

Table 1. Demographic, lifestyle and work characteristics among office workers

\begin{tabular}{|c|c|c|c|}
\hline Characteristics & & $\mathrm{n}$ & $\%$ \\
\hline \multicolumn{4}{|l|}{ Demographic } \\
\hline \multirow[t]{2}{*}{ Sex } & Female & 237 & 42.3 \\
\hline & Male & 323 & 57.7 \\
\hline \multirow[t]{4}{*}{ Age (yr) } & $19-25$ & 125 & 22.3 \\
\hline & $26-30$ & 201 & 35.9 \\
\hline & $31-40$ & 153 & 27.3 \\
\hline & $41-59$ & 81 & 14.5 \\
\hline \multirow[t]{4}{*}{$\operatorname{BMI}\left(\mathrm{kg} / \mathrm{m}^{2}\right)^{*}$} & Underweight $(<18.5)$ & 126 & 22.5 \\
\hline & Normal (18.5-23.9) & 377 & 67.3 \\
\hline & Overweight (24-27.9) & 57 & 10.2 \\
\hline & Obese $(\geq 28)$ & 0 & 0 \\
\hline \multirow[t]{2}{*}{ Education level } & High school & 36 & 6.4 \\
\hline & College/other post-high school education & 524 & 93.6 \\
\hline \multicolumn{4}{|l|}{ Lifestyle } \\
\hline \multirow[t]{2}{*}{ Smoking ${ }^{\dagger}$} & Never or seldom smoked & 409 & 73 \\
\hline & Current or past smoker & 151 & 27 \\
\hline \multirow[t]{4}{*}{ Physical exercise } & Seldom & 385 & 68.8 \\
\hline & $2-3$ times/mo & 33 & 5.9 \\
\hline & 1-2 times/wk & 79 & 14.1 \\
\hline & $\geq 3$ times/wk & 63 & 11.3 \\
\hline \multicolumn{4}{|l|}{ Work characteristics } \\
\hline \multirow[t]{4}{*}{ Period at current work (yr) } & $1.0-1.5$ & 63 & 11.3 \\
\hline & $2.0-5.0$ & 254 & 45.4 \\
\hline & $5.5-10.0$ & 113 & 20.2 \\
\hline & $\geq 10.5$ & 130 & 23.2 \\
\hline \multirow[t]{3}{*}{ Overtime work } & Often & 265 & 47.3 \\
\hline & Occasionally & 91 & 16.2 \\
\hline & Seldom & 204 & 36.4 \\
\hline \multirow[t]{2}{*}{ Job type } & Managerial & 31 & 5.5 \\
\hline & Clerical & 529 & 94.5 \\
\hline \multirow[t]{2}{*}{ Occupational status } & Part-time & 0 & 0 \\
\hline & Full-time & 560 & 100 \\
\hline
\end{tabular}

*BMI categories recommended for the Chinese population by the Working Group on Obesity in China (2002).

${ }^{\dagger}$ The smoking habits are categorized according to reference 11. 
Table 2. Descriptive statistics (mean $\pm \mathrm{SD}$ ) of individual and work characteristics among female and male office workers

\begin{tabular}{llll}
\hline & Women $(\mathrm{n}=237)$ & Men $(\mathrm{n}=323)$ & Total $(\mathrm{n}=560)$ \\
\hline Age $(\mathrm{yr})$ & $31.1( \pm 7.4)$ & $31.9( \pm 8.2)$ & $31.6( \pm 7.9)$ \\
Height $(\mathrm{cm})$ & $163.0( \pm 5.3)$ & $175.2( \pm 5.2)$ & $170.0( \pm 8.0)$ \\
Weight $(\mathrm{kg})$ & $55.2( \pm 7.3)$ & $73.9( \pm 10.7)$ & $66.0( \pm 13.2)$ \\
BMI $\left(\mathrm{kg} / \mathrm{m}^{2}\right)$ & $20.8( \pm 2.5)$ & $24.0( \pm 3.2)$ & $22.7( \pm 3.3)$ \\
Smoking* Never or seldom smoked & $229(96.6)$ & $180(55.7)$ & $409(73)$ \\
Current or past smoker & $8(3.4)$ & $143(44.3)$ & $151(27)$ \\
Employment in current job $(\mathrm{yr})$ & $7.3( \pm 6.9)$ & $7.8( \pm 7.7)$ & $7.6( \pm 7.4)$ \\
Current VDT use $(\mathrm{yr})$ & $9.11( \pm 4.24)$ & $10.30( \pm 4.13)$ & $9.80( \pm 4.22)$ \\
Overtime work* Often & $94(39.7)$ & $171(52.9)$ & $265(47.3)$ \\
\multicolumn{1}{c}{ Occasionally } & $54(22.8)$ & $37(11.5)$ & $91(16.2)$ \\
Seldom & $89(37.6)$ & $115(35.6)$ & $204(36.4)$ \\
\hline
\end{tabular}

*Each value represents the number of cases (\% of each column).

graphic characteristics of the participants. Most of them were younger than $40 \mathrm{yr}$ of age $(85.5 \%)$. Educational level of the participants was high; $93.6 \%$ of the participants had a college/other post-high school education. Only $11.3 \%$ of the participants got physical exercise more than 3 times a week.

Detailed descriptive statistics for demographic and labor characteristics of the participants are shown in Table 2. The mean age was $31.9 \mathrm{yr}$ for men and 31.1 $\mathrm{yr}$ for women. The smoking ratio for men was higher than that for women, 44.3 and $3.4 \%$, respectively. A higher proportion of men $(52.9 \%)$ often worked overtime compared with women $(39.7 \%)$.

\section{Symptom prevalence}

The results showed that the 12-month prevalences of WMSDs of the neck, shoulder, wrist/hand, upper back and low back among participants were 55.5, $50.7,31.5,26.2$ and $6.6 \%$, respectively. The highest prevalence rate of WMSDs was found in the neck region, and the lowest prevalence rate was found in the low back region.

\section{Associations between risk factors and WMSDs- $N$ \\ 1) Individual factors}

Among 8 individual factors, we found gender, education level and physical exercise were significantly associated with WMSDs-N (Table 3).

2) Working condition factors

Univariate logistic regression analysis for the association between WMSDs-N and workplace factors, showed that WMSDs-N was significantly associated with VDT operating hours per day, holding the neck in a forward bent posture for a prolonged time, often holding the neck in a flexion angle, having no breaks during work, spending less than $2 \mathrm{~h}$ before feeling tired and not having enough time for rest (Table 4).
No workstation factors were related to WMSDs-N in this research (Table 5).

\section{Multivariate analysis}

Results of the multiple logistic regression model show that individual factors and work-related factors were independently associated with prevalence of WMSDs-N (Table 6). For individual factors, only gender remained in the last model. Women had more than a 2-fold increased risk of developing WMSDs-N compared with men $(\mathrm{OR}=2.16, p<0.01)$. Six work-related factors were determined to be independently associated with prevalence of WMSDs-N. Interestingly, WMSDs-N risk was positively associated with the increase in computer use time. The odds ratio for time spent on work before feeling tired indicates that participants who tired easily had a higher chance of WMSDs-N than those who did not. A larger neck posture angle increased the likelihood of having WMSDs-N. Holding the neck at 10-20 flexion angle had an odds ratio of $2.54(95 \% \mathrm{CI}=1.56-4.14$, $p<0.000)$ compared with the reference level. Tilting the neck more than $20^{\circ}$ had about a six-fold $(95 \% \mathrm{CI}=1.73-18.97, p<0.000)$ risk compared with the reference level.

\section{Discussion}

The results of this study show that WMSDs are widespread and relatively severe in office workers in Beijing, China. In addition, the present study indicates that VDT work is closely associated with the prevalence of WMSDs-N.

\section{The prevalence of WMSDs}

The first aim of this study was to estimate the 12-month prevalences of WMSDs among office workers in Beijing. The results show that the highest 
Table 3. Odds ratio (OR) with $95 \%$ confidence interval (95\% CI) of office workers with and without WMSDs-N for demographic, lifestyle and work characteristics among office workers

\begin{tabular}{|c|c|c|c|c|c|}
\hline & & \multirow{2}{*}{$p$ value } & \multirow{2}{*}{ OR } & \multicolumn{2}{|c|}{$95 \% \mathrm{CI}$} \\
\hline & & & & Lower & Upper \\
\hline \multicolumn{6}{|l|}{ Demographic } \\
\hline \multirow[t]{2}{*}{ Sex } & Male & Reference & & & \\
\hline & Female & 0.00 & 2.26 & 1.47 & 3.48 \\
\hline \multirow[t]{4}{*}{ Age (yr) } & $19-25$ & Reference & & & \\
\hline & $26-30$ & 0.21 & 0.73 & 0.45 & 1.20 \\
\hline & $31-40$ & 0.50 & 0.81 & 0.44 & 1.49 \\
\hline & $41-59$ & 0.76 & 0.89 & 0.41 & 1.90 \\
\hline \multirow[t]{3}{*}{$\operatorname{BMI}\left(\mathrm{kg} / \mathrm{m}^{2}\right)^{*}$} & Underweight $(<18.5)$ & Reference & & & \\
\hline & Normal (18.5-23.9) & 0.12 & 0.61 & 0.34 & 1.13 \\
\hline & Overweight (24-27.9) & 0.56 & 1.15 & 0.72 & 1.84 \\
\hline \multirow[t]{2}{*}{ Education level } & High School & Reference & & & \\
\hline & College/other post high school education & 0.02 & 2.43 & 1.17 & 5.04 \\
\hline \multicolumn{6}{|l|}{ Lifestyle } \\
\hline \multirow[t]{2}{*}{ Smoking ${ }^{\dagger}$} & Never or seldom smoked & Reference & & & \\
\hline & Current or past smoker & 0.12 & 1.42 & 0.91 & 2.22 \\
\hline \multirow[t]{4}{*}{ Physical exercise } & $\geq 3$ times/wk & Reference & & & \\
\hline & Seldom & 0.04 & 1.77 & 1.00 & 3.13 \\
\hline & 1-2 times/wk & 0.16 & 1.90 & 0.77 & 4.66 \\
\hline & $2-3$ times/mo & 0.65 & 1.18 & 0.58 & 2.39 \\
\hline \multicolumn{6}{|l|}{ Work characteristics } \\
\hline \multirow[t]{4}{*}{ Period at current work (yr) } & $1.0-1.5$ & Reference & & & \\
\hline & $2.0-5.0$ & 0.09 & 1.69 & 0.93 & 3.08 \\
\hline & $5.5-10.0$ & 0.12 & 1.74 & 0.87 & 3.50 \\
\hline & $\geq 10.5$ & 0.08 & 1.97 & 0.93 & 4.19 \\
\hline \multirow[t]{2}{*}{ Job type } & Managerial & Reference & & & \\
\hline & Clerical & 0.96 & 0.98 & 0.45 & 2.15 \\
\hline
\end{tabular}

*BMI categories recommended for the Chinese population by the Working Group on Obesity in China (2002).

The smoking habits are categorized according to reference 11.

12-month prevalence rate of WMSDs was related to the neck region $(55.5 \%)$, which agrees with previous studies in which the prevalence rate ranged from $27-63 \%{ }^{13)}$. The prevalence rate of low back WMSDs was lowest and lower than the rates in previous studies, which ranged from7.4-57.6\% ${ }^{8,17)}$. The different prevalence rates between studies may be caused by a lack of internal standard definition of WMSDs, resulting in a different case definition and data collection procedures between various studies ${ }^{18}$. They may also be partially attributed to different study populations, social economics and customs.

\section{Individual factors}

Many individual factors including age, gender, BMI and education level may play a role in causing WMSDs-N. Our results showed that gender, education level and physical exercise were related to WMSDs-N, but only gender was an independent risk factor.
The prevalence of WMSDs-N was substantially higher among women (64.6\%) than men (46.7\%) in our study, which is consistent with previous studies $^{19,20)}$. Women appear to consistently report more neck and upper extremity symptoms than men ${ }^{21)}$. In this study, even though males had a higher BMI, longer employment than females, a significant higher proportion of smokers and often had jobs requiring overtime, women had more than twice the risk of suffering from WMSDs-N compared with men.

The gender difference may be explained by many factors, one of which could be that the women had in which they were more often exposed to physical and psychosocial risk factors compared with men ${ }^{22)}$. This may also explained partially by women having a smaller stature and weaker muscles than men $^{3}$. As most workplaces are designed on the basis of anthropometric data from men, women might work with a higher relative musculoskeletal load when performing the same tasks as men; for instance, they may use a 
Table 4. Odds ratio (OR) with $95 \%$ confidence interval (95\% CI) of office workers with and without WMSDs-N for the workplace factors

\begin{tabular}{|c|c|c|c|c|}
\hline & \multirow{2}{*}{$p$ value } & \multirow{2}{*}{ OR } & \multicolumn{2}{|c|}{$95 \% \mathrm{CI}$} \\
\hline & & & Lower & Upper \\
\hline Years of using a computer at work & 0.99 & 0.92 & 0.83 & 1.06 \\
\hline \multicolumn{5}{|l|}{ Using personal computer in spare time } \\
\hline No & Reference & & & \\
\hline Yes & 0.87 & 0.96 & 0.60 & 1.53 \\
\hline \multicolumn{5}{|l|}{ VDT operating hours per day (h) } \\
\hline $1.0-4.0$ & Reference & & & \\
\hline $4.5-7.5$ & 0.02 & 2.15 & 1.13 & 4.11 \\
\hline $8.0_{-}$ & 0.00 & 2.84 & 1.42 & 5.68 \\
\hline \multicolumn{5}{|l|}{ Overtime work } \\
\hline Seldom & Reference & & & \\
\hline Occasionally & 0.68 & 0.85 & 0.40 & 1.82 \\
\hline Often & 0.18 & 1.68 & 0.77 & 3.65 \\
\hline \multicolumn{5}{|c|}{$\begin{array}{l}\text { Holding the neck in a forward bent posture } \\
\text { for a prolonged time }\end{array}$} \\
\hline No & Reference & & & \\
\hline Yes & 0.04 & 1.72 & 1.00 & 2.99 \\
\hline \multicolumn{5}{|c|}{ Often holding the neck at a flexion angle* } \\
\hline Neck bent $\leq 10^{\circ}$ & Reference & & & \\
\hline Neck bent $10-20^{\circ}$ & 0.00 & 2.42 & 1.47 & 4.00 \\
\hline Neck bent $\geq 20^{\circ}$ & 0.00 & 5.50 & 1.63 & 18.55 \\
\hline \multicolumn{5}{|c|}{ Have breaks during work (except lunch time) } \\
\hline Yes & Reference & & & \\
\hline No & 0.61 & 0.77 & 0.28 & 2.13 \\
\hline \multicolumn{5}{|l|}{ Have enough rest time } \\
\hline Yes & Reference & & & \\
\hline No & 0.02 & 1.58 & 1.07 & 2.32 \\
\hline \multicolumn{5}{|c|}{ Time spent at work before taking a break (h) } \\
\hline-2.0 & Reference & & & \\
\hline $2.5-3.5$ & 0.97 & 1.01 & 0.60 & 1.69 \\
\hline $3.5-$ & 0.87 & 1.04 & 0.58 & 1.87 \\
\hline \multicolumn{5}{|c|}{ Time spent at work before feeling tired (h) } \\
\hline $4.5-$ & Reference & & & \\
\hline $2.5-4.0$ & 0.16 & 1.38 & 0.87 & 2.17 \\
\hline $0-2.0$ & 0.02 & 1.83 & 1.12 & 3.01 \\
\hline
\end{tabular}

*The neck angle is categorized according to the Rapid Upper Limb Assessment (RULA) ${ }^{15}$.

greater range of motion to work with the mouse $\mathrm{e}^{23)}$. Moreover, some studies have shown that women are at greater risk of presenting WMSDs probably due to the effect of their dual role as workers and housewives (such as differences in household work and childcare $)^{24)}$.

\section{Workplace factors}

Daily time spent on a computer has been significantly associated with WMSDs-N. The results of the present study further confirm this association; WMSDs-N risk increases with time spent on a computer. A cross-sectional study found that the percent of workers reporting "almost daily" neck discomfort increased monotonically with increasing hours of daily VDT use ${ }^{25)}$. Knave et $a l .{ }^{26)}$ reported a relationship between hours of VDT use per day and "musculoskeletal complaints" for women. Rossignol et $a{ }^{27)}$ found that individuals who had 7 or more hours of daily VDT use had a significantly elevated odds ratio for musculoskeletal complaints in comparison with nonusers. Faucett and Rempel ${ }^{28)}$ reported an odds ratio of $1.44(95 \% \mathrm{CI}=1.03-1.99)$ for the association between hours of daily VDT use and potential upper torso disorders. Polanyi et al. ${ }^{16)}$ reported that after adjusting for confounders including demographic, ergonomic and psychosocial factors, individuals who 
Table 5. Odds ratio (OR) with $95 \%$ confidence interval (95\% CI) of office workers with and without WMSDs-N for the workstation factors

\begin{tabular}{|c|c|c|c|c|}
\hline \multirow{3}{*}{ Use LCD } & \multirow{2}{*}{$p$ value } & \multirow{2}{*}{$\mathrm{OR}$} & \multicolumn{2}{|c|}{$95 \% \mathrm{CI}$} \\
\hline & & & \multirow[t]{2}{*}{ Lower } & \multirow[t]{2}{*}{ Upper } \\
\hline & & & & \\
\hline Yes & Reference & & & \\
\hline No & 0.89 & 0.95 & 0.49 & 1.86 \\
\hline \multicolumn{5}{|l|}{ Type of VDT } \\
\hline Desktop & Reference & & & \\
\hline Laptop & 0.62 & 0.78 & 0.29 & 2.08 \\
\hline Both & 0.22 & 0.68 & 0.38 & 1.26 \\
\hline \multicolumn{5}{|l|}{ Monitor position } \\
\hline In front & Reference & & & \\
\hline To the side & 0.45 & 1.22 & 0.71 & 2.09 \\
\hline \multicolumn{5}{|c|}{ Main operating tools while operating } \\
\hline Both & Reference & & & \\
\hline Keyboard & 0.62 & 0.78 & 0.29 & 2.07 \\
\hline Mouse & 0.21 & 0.68 & 0.37 & 1.26 \\
\hline \multicolumn{5}{|c|}{ Forearm position parallel to the floor while working } \\
\hline Yes & Reference & & & \\
\hline No, wrist above elbow & 0.89 & 0.96 & 0.60 & 1.54 \\
\hline No, wrist below elbow & 0.29 & 1.33 & 0.77 & 2.28 \\
\hline \multicolumn{5}{|c|}{ Ability to rest wrists on desk top while working } \\
\hline No & Reference & & & \\
\hline Yes & 0.26 & 0.80 & 0.54 & 1.17 \\
\hline \multicolumn{5}{|c|}{ Ability to rest forearms on desk top while working } \\
\hline No & Reference & & & \\
\hline Yes & 0.33 & 1.23 & 0.80 & 1.87 \\
\hline \multicolumn{5}{|l|}{ Chair height adjustable } \\
\hline Yes & Reference & & & \\
\hline No & 0.63 & 1.14 & 0.65 & 2.03 \\
\hline \multicolumn{5}{|l|}{ Chair has an adjustable backrest } \\
\hline Yes & Reference & & & \\
\hline No & 0.59 & 1.12 & 0.73 & 1.71 \\
\hline \multicolumn{5}{|l|}{ Chair has a five-star castor base } \\
\hline Yes & Reference & & & \\
\hline No & 0.63 & 0.83 & 0.38 & 1.79 \\
\hline
\end{tabular}

reported keying $5 \mathrm{~h}$ per day had significantly greater prevalence of MSD (including neck) than those keying $1.5 \mathrm{~h}$ per day $(\mathrm{OR}=1.61,95 \% \mathrm{CI}=1.16-2.25)$.

Often holding the neck in a forward bent posture for a prolonged time was positively associated with WMSDs-N. Cagnie et al..$^{29)}$ and Julius Sim et al. ${ }^{30}$ both reported an odds ratio of 2.0 for the relation between hours of prolonged bending of the neck and neck complaints.

An increased risk of WMSDs-N was significantly associated with the increased neck flexion angle. Ariens et al. $^{31)}$ found a trend for a positive relation between neck flexion and neck problem. Ohlsson et $a l .{ }^{32)}$ reported that often holding the neck at a flexion of $15^{\circ}$ was significantly related to neck disor- ders. Bernard ${ }^{33)}$ illustrated that awkward neck posture held for a prolonged time was a risk factor for neck problems. Tilting the neck more than $30^{\circ}$ greatly increased the rate of fatigue in the neck muscles.

The neck supports the head, which makes up approximately one-seventh of the total body weight. When the neck is bent, the head partially lose the support of the spine. Thus, in order to keep the head in the bent position, the small spinal muscles work twice as hard as normal. In this position, neck muscles must do much of the work to keep the head steady. Therefore, they become overloaded and finally injured $^{34)}$.

Having breaks during work and having enough rest time were significantly associated with WMSDs-N. 
Table 6. Factors remaining in the final multivariate logistic regression model for office workers with and without WMSDs-N

\begin{tabular}{|c|c|c|c|c|}
\hline & \multirow{2}{*}{$p$ value } & \multirow{2}{*}{ OR } & \multicolumn{2}{|c|}{$95 \% \mathrm{CI}$} \\
\hline & & & Lower & Upper \\
\hline \multicolumn{5}{|l|}{ Gender } \\
\hline Male & Reference & & & \\
\hline Female & 0.00 & 2.16 & 1.48 & 3.15 \\
\hline \multicolumn{5}{|c|}{ VDT operating hours per day (h) } \\
\hline$\leq 4.0$ & Reference & & & \\
\hline $4.5-7.5$ & 0.02 & 2.09 & 1.14 & 3.83 \\
\hline$\geq 8.0$ & 0.00 & 2.83 & 1.46 & 5.49 \\
\hline \multicolumn{5}{|c|}{ Holding the neck in a forward bent posture for a long time } \\
\hline No & Reference & & & \\
\hline Yes & 0.04 & 1.73 & 1.01 & 2.96 \\
\hline \multicolumn{5}{|c|}{ Often holding the neck at a flexion angle* } \\
\hline Neck bent $\leq 10^{\circ}$ & Reference & & & \\
\hline Neck bent $10-20^{\circ}$ & 0.00 & 2.54 & 1.56 & 4.14 \\
\hline Neck bent $\geq 20^{\circ}$ & 0.00 & 5.73 & 1.73 & 18.97 \\
\hline \multicolumn{5}{|c|}{ Time spent at work before feeling tired (h) } \\
\hline$\geq 4.5$ & Reference & & & \\
\hline $2.5-4.0$ & 0.16 & 1.36 & 0.88 & 2.10 \\
\hline$\leq 2.0$ & 0.01 & 1.82 & 1.13 & 2.93 \\
\hline \multicolumn{5}{|l|}{ Have breaks during work } \\
\hline Yes & Reference & & & \\
\hline No & 0.03 & 1.71 & 1.05 & 2.76 \\
\hline \multicolumn{5}{|l|}{ Have enough rest time } \\
\hline Yes & Reference & & & \\
\hline No & 0.01 & 1.63 & 1.12 & 2.37 \\
\hline
\end{tabular}

*The neck angle is categorized according to the Rapid Upper Limb Assessment (RULA) ${ }^{15}$.

The protective effect of rest breaks was also reported in previous epidemiology studies ${ }^{29,35)}$. EMG muscle monitoring results confirmed this conclusion $^{36)}$. Breaks reduce VDT exposure, allow a reduction in the muscle load due to poor ergonomics conditions and allow muscle relaxation and recovery ${ }^{37}$. Winkel and Oxenburgh $^{38)}$ stated that the way to relieve neck and shoulder discomfort in VDT work is to increase rest breaks.

In this study, we found that time spent on work before feeling tired was associated with WMSDs-N. Many researches confirmed that tiredness is one of the risk factors for WMSDs ${ }^{29}$. Our study further indicated that office workers who tire more easily are more likely to have WMSDs-N.

Surprisingly, no workstation factors were related to WMSDs- $\mathrm{N}$ in this study, which might be caused by the population having computer workstations with good ergonomic designs.

\section{Limitations of this study}

Information about musculoskeletal symptoms and related factors were obtained by the self-reporting method, which may lead to over- or underestimation of WMSDs. Many researchers reported differences between self-reporting and observation of others in prevalence rates of WMSDs and physical work ${ }^{5,39)}$, but others did not find such an effect ${ }^{40}$. In China, WMSDs are still not included as occupational diseases, and the awareness of WMSDs as an occupational injury is relatively low; so, theirs is no reporting bias, which may be influenced by reported discomfort.

This limited our ability to assess the causal relationship between variables and the possibility of a firm conclusion from the correlations observed in our study. However, our findings were consistent with those in reports of other research.

Future studies should be carried out directly towards development of prevention programs using the results gathered in this survey.

\section{Preventive measures}

Considering the prevalence of WMSDs in the present study, effective preventive measures should focus on neck disorders. The multivariable analyses showed that neck symptoms occurred less frequently 
when VDT exposure was low or rest breaks are taken. Therefore, office workers should be advised to take regular breaks to minimize the impact of office work. Regular breaks have been confirmed to reduce discomfort in the neck in VDT workers without affecting productivity ${ }^{36)}$.

In conclusion, the prevalence rates of WMSDs among office workers in Beijing, China, were relatively high compared with the studies in other countries. The most commonly affected body part was the neck, while the low back was least commonly affected. Both workplace and individual factors were strongly associated with WMSDs-N. The most important risk factor was using computers for long periods without taking enough breaks. Therefore, rest breaks could be effective as a preventive measure to reduce the impact office work.

Acknowledgments: The study was supported by the National Science and Technology Infrastructure Program of China (No. 2006BAI06B08). The authors would like to thank the participants for their participation in this study.

\section{References}

1) China Statistical Yearbook: By industry / employment size of the use of personal computers, connected to the Internet or a Web page/the number of Web site units. Beijing: National Bureau of Statistics of the People's Republic of China. [Online]. 2008 [cited 2008 Sept 21]; Available from: URL: http://www.stats.gov.cn/tjsj/ndsj/2008/html/W2349c. html

2) Dane D, Feuerstein M, Huang G. Measurement properties of a self-report index of ergonomic exposures for use in an office environment. J Occup Environ Med 2002; 44: 73-81.

3) Korhonen T, Ketola R, Toivonen R, et al. Work related and individual predictors for incident neck pain among office employees working with video display units. Occup Environ Med 2003; 60: 475-82.

4) Blatter BM, Bongers PM. Duration of computer use and mouse use in relation to musculoskeletal disorders of neck or upper limb. Int J Ind Ergon 2002; 30: 295-306.

5) Klussmann A, Gebhardt H, Liebers F, Rieger MA. Musculoskeletal symptoms of the upper extremities and the neck: a cross sectional study on prevalence and symptom -predicting factors at visual display terminal (VDT) workstations. BMC Musculoskelet Disord 2008; 9: 96

6) Melhorn JM. The impact of workplace screening on the occurrence of cumulative trauma disorders and workers' compensation claims. J Occup Environ Med 1999; 41: 84-92.

7) Nicholas RA, Feuerstein M, Suchday S. Work style and upper extremity symptoms: a biobehav- ioral perspective. J Occup Environ Med 2005; 47: 352-61.

8) Sillanpää J, Huikko S, Nyberg $M$, et al. Effect of work with visual display units on musculo-skeletal disorders in the office environment. Occup Med 2003; 53: 443-51.

9) Carter JB, Banister EW. Musculoskeletal problems in VDT work: review. Ergonomics 1994; 37: $1623-48$.

10) Kourinka I, Jonsson B, Kilbom A. Standardised Nordic questionnaires for the analysis of musculoskeletal systems. Appl Ergon 1987; 18: 233-7.

11) Johnstona V, Souvlisa T, Jimmiesonb NL, Jull G. Associations between individual and workplace risk factors for self-reported neck pain and disability among female office workers. Appl Ergon 2008; 39: 171-82.

12) Hildebrandt VH, Bongers PM, vanDijk FJ, Kemper HC, Dul J. Dutch musculoskeletal questionnaire: description and basic qualities. Ergonomics 2001; 44: 1038-55.

13) Ortiz-Hernádez L, Tamez-González S, MartínezAlcántara S, Méndez-Ramírez I. Computer Use Increases the risk of musculoskeletal disorders among newspaper office workers. Archives of Medical Research 2003; 34: 331-42.

14) Queensland Government. Workplace Health and Safety, Q. Ergonomics workstations for keyboard operators. Brochure 031, 1997.

15) Mcatamney L, Corlett EN. RLUA: a survey method for the investigation of work-related upper limb disorders. Appl Ergon 1993; 24: 91-9.

16) Polanyi MFD, Cole DC, Beaton DE, et al. Upper limb work-related musculoskeletal disorders among newspaper employees: cross-sectional survey results. Am J Ind Med 1997; 32: 620-8.

17) Juul-Kristensen B, Sogäärd K, Stroyer J, Jensen C. Computer users' risk factors for developing shoulder, elbow and back symptoms. Scand J Work Environ Health 2004; 30: 390-8.

18) Boocock MG, Collier JMK, McNair PJ, et al. A framework for the classification and diagnosis of work-related upper extremity conditions: systematic review. Semi Arthritis Rheum 2009; 38: 296-311.

19) Viikari-Juntura E, Martikainen R, Luukkonen R, et al. Longitudinal study on work related and individual risk factors affecting radiating neck pain. Occup Environ Med 2001; 58: 345-52.

20) Treaster DE, Burr D. Gender differences in prevalence of upper extremity musculoskeletal disorders. Ergonomics 2004; 47: 495-526.

21) Punnett L, Bergqvist U. Visual display unit work and upper extremity musculoskeletal disorders. Stockholm: National Institute for Working Life; 997.

22) Karlqvista L, Tornqvista EW, Hagberg M. Selfreported working conditions of VDU operators and associations with musculoskeletal symptoms: a cross-sectional study focussing on gender differences. Int J Ind Ergon 2002; 30: 277-94.

23) Karlqvist L.Computer mouse and trac-ball operation: 
similarities and differences in posture, muscular load and perceived exertion. Int J Ind Ergon 1999; 23: 157-69.

24) Yu IT, Wong TW. Musculoskeletal problems among VDU workers in a Hong Kong bank. Occup Med (Lond) 1996; 46: 275-80.

25) Canadian Labor Congress. Towards a more humanized technology: exploring the impact of video display terminals on health and working conditions of Canadian office workers. Ontario (Canada): Canadian Labor Congress; 1982.

26) Knave BG, Wibom RI, Voss M, Hedstrom LD, Bergqvist UOV. Work with video display terminals among office employees, Subjective symptoms and discomfort. Scand J Work Environ Health 1985; 11: 457-66.

27) Rossignol AM, Morse EP, Summers VM, Pagnotto LD. Video display terminal use and reported health symptoms among Massachusetts clerical workers. J Occup Med 1987; 29: 112-8.

28) Faucett J, Rempel. VDT-related musculoskeletal symptoms: interactions between work posture and psychosocial work factors. Am J Ind Med 1994; 26: 597-612.

29) Cagnie B, Danneels L, Van Tiggelen D, De Loose $\mathrm{V}$, Cambier D. Individual and work related risk factors for neck pain among office workers: a cross sectional study. Eur Spine J 2007; 16: 679-86.

30) Sim J, Lacey RJ, Lewis M. The impact of workplace risk factors on the occurrence of neck and upper limb pain: a general population study. BMC Public Health 2006; 6: 234.

31) Ariens G, Bongers P, Douwes M, et al. Are neck flexion, neck rotation and sitting at work risk factors for neck pain? Results of a prospective cohort study. Occup Environ Med 2001; 58: 200-7.
32) Ohlsson K, Attewell R, Paisson B. Repetitive industrial work and neck and upper limb disorders in females. Am J Ind Med 1995; 27: 731-47.

33) Bernard BP. A critical review of epidemiologic evidence for work-related musculoskeletal disorders of the neck, upper extremity, and low back. Musculoskeletal disorders and workplace factors. Cincinnati (OH): National Institute for Occupational Safety and Health (NIOSH); 1997.

34) Harrison DE. Comparison of axial and flexural stresses in lordosis and three buckled configurations of the cervical spine. Clin Biomech (Bristol, Avon) 2001; 16: 276-84.

35) Galinsky TL, Swanson NG, Sauter SL, Hurrel JJ, Schleifer LM. A field study of supplementary rest breaks for data-entry operators. Ergonomics 2000; 43: 622-38.

36) McLean L, Tingley M, Scott RN, Rickards J. Computer terminal work and the benefit of microbreaks. Appl Ergon 2001; 32: 225-37.

37) Ortiz-Herna L, Tamez-Gonza LS, Mart AS. Computer Use Increases the risk of musculoskeletal disorders among newspaper office workers. Archives of Medical Research 2003; 34: 331-42.

38) Winkel J, Oxenburgh. Towards optimizing physical activity in VDT/office work. Promoting Health and Productivity in the Computerized Office. Edited by Sauter S, Dainoff M, and Smith M. London: Taylor \& Francis; 1990: 94-117.

39) Dickinson CE, Campion K, Foster AF, et al. Questionnaire development: an examination of the Nordic musculoskeletal questionnaire. Appl Ergon 1992; 23: 197-201.

40) Frymoyer JW, Pope MH, Clements JH, et al. Risk factors in low back pain. J Bone \& Joint Surg 1983; 65: $213-8$. 